\title{
AVALIAÇÃO DO DESEMPENHO DOCENTE E GESTÃO ESCOLAR: REFLEXOS NA GESTÃO INTERMÉDIA E EFEITOS DE REVERTICALIZAÇÃO NA HIERARQUIA DE ESCOLA
}

\author{
Henrique M. Pereira RAMALHO ${ }^{1}$
}

RESUMO: Decorrente de uma investigação de doutoramento, procuramos, neste texto, fazer uma abordagem crítica à relação estabelecida entre a avaliação de desempenho dos docentes e a emergência de "novas" lideranças intermédias de um agrupamento de escolas, no quadro do sistema da educação básica em Portugal, aludindo ao modo como essas "novas" lideranças têm vindo a ocupar os seus espaços na administração e gestão da escola básica portuguesa. Congruentemente, apresenta-se na configuração de um ensaio sóciocrítico de carácter iminentemente conclusivo daquela mesma investigação, também suportado por um modelo teórico analítico que subsidiou teoricamente a pesquisa. No geral, inscrevemos este nosso ensaio na metodologia específica do estudo de caso, tendo recorrido a diferentes técnicas de pesquisa e recolha de dados, designadamente, o questionário, a entrevista, documentos pessoais críticos e análise de documentos oficiais oriundos da administração central (legislação) e do agrupamento de escolas observado. Concludentemente, observamos a percepção de algumas fragilidades e, até, ruturas com o reconhecimento e legitimação daquelas lideranças intermédias, muito particularmente quando são identificadas como lideranças a quem é atribuída a responsabilidade pela gestão e execução da avaliação.

PALAVRAS-CHAVE: Avaliação de professores. Lideranças intermédias. Burocracia. Gestão escolar.

\section{INTRODUÇÃO}

Este texto decorre de uma análise das interações institucionais e sócioorganizacionais que procuram dar conta das intermitências multidiscursivas entre o macro, o meso e o microestrutural dos movimentos, ora mais convergentes, ora mais divergentes, alusivas à avaliação do desempenho de professores na escola básica portuguesa (RAMALHO, 2012). Fazemo-lo com destaque para as alterações ocorridas no âmbito da gestão periférica e das manifestações meso e microdiscursivas suportadas por uma alegada "nova" estrutura hierárquica da periferia, recentemente institucionalizada no quadro das atuais políticas e práticas de avaliação do desempenho de professores. Realça-se, muito particularmente, o sentido e o significado dados às microdiscursividades segundo uma lógica de diferenciação estratégica de caráter adaptativo, dissentimento, conflito, performance individual e de competição entre pares,

1 ESTGV - Escola Superior de Tecnologia e Gestão do Viseu. Instituto Politécnico de Viseu Departamento de Psicologia e Ciências da Educação. Viseu - Portugal. 3504-510 hpramalho@esev.ipv.pt 
em que, decorrentemente, são analisadas as tensões, as oportunidades e os dilemas advindos das dinâmicas associadas aos efeitos da prescrição central da avaliação, ao ato de "avaliar" e à experiência de "ser avaliado" em contextos mais restritos.

Decorrente de uma investigação enquadrada na metodologia específica do estudo de caso, onde o investigador recorreu a um processo de triangulação de dados empíricos oriundos da aplicação de entrevistas semiestruturadas, da análise documental e, ainda, ao questionário autoadministrado a todos os docentes da unidade escolar observada (RAMALHO, 2012), é um texto suportado por uma abordagem metodológica e empírica, cujo enfoque nos alinha com a possibilidade de perspetivar a ação organizacional e pedagógica de um agrupamento de escolas como estando condicionada por critérios de conduta e motivação da atividade docente próximos da competição, performance, ritualização e, até mesmo, do conflito entre docentes. Pensamos que, a propósito, fez todo o sentido preocuparmo-nos com questões que pudessem problematizar os processos, a hierarquia, as lideranças e as expectativas, os efeitos e as consequências advindas da implementação das políticas de avaliação de professores. Por conseguinte, distanciámo-nos das orientações teóricas da gestão e administração que não reconhecem os diferentes tipos de interesses dos sistemas organizacionais (BALL, 1989), suscitando-se um trabalho de análise sociocrítica, que define a nossa ambição de imergir no contexto organizacional com uma relativa profundidade, para que se identifiquem consensos e dissentimentos, alianças e táticas mais individualistas, pluralidades e homogeneidades que, de alguma forma, configuram as dinâmicas dos meso e micro contextos escolares (OLIVEIRA, 2013).

Tal opção metodológica provocou a emergência de múltiplas questões orientadoras (LUDKE; ANDRÉ, 1986) tradutoras do nosso objeto de estudo em construção sujeito a um exercício de "compreensão sociológica" ou, pelo menos, não definitivamente construído.

No presente ensaio, concretizámos apenas uma de várias linhas analíticointerpretativas - e necessariamente conclusivas - dos nossos dados empíricos, segundo um ângulo de discussão que procura alinhar-se pelos seguintes pontos críticos: i) Quais as transformações mais relevantes que poderíamos observar entre a velha hierarquia de tendência horizontal e a mais recente verticalização das relações de poder, de autoridade e de influência na escola e na sala de aula? ii) Em consequência, como podem ser caracterizados os atuais padrões culturais 
associados ao novo clima organizacional de escola, dentro de uma perspetiva de poder, influência, liderança e conflito entre docentes? iii) Poderemos estar a falar de efeitos de desagregação socioprofissional no seio da classe docente?

Procuramos debater a confrontação do poder, da autoridade e das influências que as estruturas de gestão intermédias exercem ao nível da consolidação da avaliação do desempenho docente e, consequentemente, ao nível do impacto e uso do poder de avaliar de que estão investidas. Um debate que é equacionado na perspetiva dos movimentos de maior convergência/divergência inerentes à avaliação, chamando a atenção para o sentido e significado dos loci meso e micropolítico, segundo lógicas de reprodução, diferenciação, dissentimento, conflito, performance individual e de competição entre pares. Discute-se a instrumentalização daquelas lideranças em prol da (re)centralização, da (re)verticalização, da (re)burocratização e da despolitização dos contextos e processos de tomada de decisão e gestão educativa, que, por adotarem uma configuração de "repartições locais de gestão" da administração central, tendem a comportarem-se como unidades de liderança especialmente vocacionadas para a extração de contas acerca do desempenho docente, adotando, para tal, práticas de gestão tipicamente reprodutoras do instrumento burocrático central e descaracterizando eventuais possibilidades de consolidação de práticas avaliativas mais autónomas face ao referencial central.

\section{AS LÓGICAS DIFERENCIADORAS DO ENGAJAMENTO BUROCRÁTICO NA EMERGÊNCIA DE "NOVAS” LIDERANÇAS INTERMÉDIAS}

A nossa análise orienta-nos, claramente, para uma interpretação que admite uma dupla perspectiva de compreensão dos sentidos e significados das diretrizes microdiscursivas: sendo que emerge algo difusa a interpretação dos indicadores respetivos assume-se disseminada e sistematizada segundo um modelo de leitura que se desenvolve entre uma perspectiva diferenciadora e uma orientação fragmentária da avaliação do desempenho docente (MARTIN; SIEHL, 1983).

No quadro geral dos nossos dados empíricos, ao destacarmos, por exemplo, determinados indicadores em que prevalece o interesse individualista de carreira e a consequente concepção individualista do desempenho docente, segundo uma lógica de empreendimento individual, ingressamos numa lógica interpretativa que nos adverte para a responsabilidade individual versus trabalho colaborativo, assistindo-se a um 
interesse exacerbado na distinção profissional pelo mérito individual motivada, antes de tudo, pela racionalidade subjetiva e pela ambição desenvolvida em torno da melhor qualificação profissional, sobretudo quando inserida na perspectiva da distinção profissional jogada ao nível dos ganhos e perdas decorrentes da avaliação. Isto que dizer que, se por um lado, os atores da periferia, quando sedeados no respetivo locus micropolítico, desenvolvem sentidos e significados fragmentários acerca das políticas e práticas de avaliação do seu desempenho, fazem-no de uma forma claramente implícita, espontânea e suficientemente efémera para que tais sentidos e significados sejam substituídos pela tendência para adotarem um engajamento burocrático motivado, antes de tudo, pela propensão que cada ator ou pequenos grupos apresentam para se adaptarem às regras do "jogo" oficialmente prescritas, não porque simplesmente concordam com elas, mas discordando delas, procuram desenvolver mecanismos que promovam a sua adaptação estratégica ao sistema de avaliação, em linha com o que já antes referimos a propósito da "narrativa da normalização" e respetivo "referencial burocrático" (RAMALHO, 2012, p.253). Os dados empíricos mostram que ao serem comprometidos pelo efeito prescritor das regras oficiais da avaliação, os atores tendem a inserir-se numa lógica de consentimento relativo por via da cultura de objetivos, que enfatiza um determinado quadro de objetivos de desempenho definidos, opcionalmente, por eles próprios e, simultaneamente, por via da cultura de regras (NEVES, 2001), pelas quais se sentem seduzidos, convencidos ou arrolados por via da formalização, pela segurança da padronização e do caráter centralista, em nome da sua própria estabilidade e segurança, seja na perspetiva de avaliados, seja na perspetiva de avaliadores. Neste caso, os atores enquadram-se numa perspetiva cultural da avaliação do seu desempenho claramente diferenciadora e ortogonal (MARTIN; SIEHL, 1983; MARTIN, 1992).

Consequentemente, os nossos dados empíricos mostram que o engajamento burocrático envolve, também, os atores colocados na situação de "avaliados", igualmente submetidos aos requisitos centro-administrativos, em que a sua avaliação resulta de um isomorfismo procedimental pré-determinado pelo mando administrativo e quase mimeticamente reproduzido pelas instâncias periféricas a quem estão cometidas as funções de gestão e execução da avaliação, inscrevendo a avaliação de professores no quadro mais geral das políticas educativas como uma tecnologia social com funções regulatórias, “[...] produzindo comportamentos ou regras e padrões que agem a partir de um processo de autodisciplina” (JAEHN; FERREIRA, 2012, p.265). 
Desenvolvemos, assim, uma perspetiva interpretativa que coloca os "avaliados" no locus micropolítico segundo a perspetiva do conflito e da performance individual, que denuncia, em alguma medida, a competição entre pares como campo conflituoso, motivado, muito particularmente, por um maior incremento organizacional, curricular e pedagógico do interesse de carreira (MORGAN, 1996), pela "melhor nota" em prol da "melhor carreira", atendendo, primeiramente, às suas próprias necessidades no trabalho (ORTSMAN, 1984), mesmo que em contracorrente com a conceção efetiva do "melhor profissional", a que subjaz uma certa negação do "mito da nota verdadeira" (HADJI, 1994, p.101).

Simultaneamente, os dados empíricos denunciam um sentido geral da lógica da “dedicação máxima” à profissão decorrente das expectativas que os docentes desenvolvem e mantêm acerca da sua profissão (GIBSON; IVANCEVICH; DONNELLY, 1988) e dos fenómenos de competição e de conflito que, efetivamente, parecem, instrumentalmente, marcar o sentido e o significado atribuído à própria avaliação do desempenho, designadamente em termos de ganhos e de perdas profissionais; circunstâncias estas que os levam a adotar posições mais diferenciadoras e ortogonais, necessariamente decorrentes dos posicionamentos estratégicos individuais, visando, fundamentalmente, a adaptação de cada um (ou cada grupo) ao esquema burocrático instituído, adotando um comportamento típico de atores que aceitam adaptar-se às regras do "jogo" como forma de "salvar a face", de "levar a melhor" sobre os outros (SANTOS GUERRA, 1995) e, eventualmente, "contornar o sistema”, num perfeito exercício de adesão estratégica às regras centrais. Neste caso, o mito da competência técnica, estando fortemente conectado à prerrogativa de "ser professor", tende a neutralizar a capacidade crítica dos professores para reagirem aos constrangimentos centro burocráticos, organizacionais e profissionais, reconceptualizando, continua e estrategicamente, os "sistemas de ação concreta", fazendo uso das respetivas margens de autonomia relativa (CROZIER; FRIEDBERG, 1977), mesmo estando submetidos ao "contrato psicológico" e ao consequente "conformismo para a ideologia do agrupamento" (BERNARDES, 1990, p.180) que lhe subjaz.

Evidencia-se uma configuração formal e racional da hierarquia consolidada pelas políticas de avaliação de professores e educadores, que configura possibilidades diferenciadas de ascensão na carreira e o acesso aos cargos de topo limitado a um número reduzido de atores, ilustrando uma orientação para a ação tendencialmente 
individualista, em detrimento do trabalho cooperativo, o que, na realidade, sugere uma dimensão conflituante (MORGAN, 1996).

Decorrentemente, uma das justificações que os docentes apontam com mais insistência para explicar as condutas meritocráticas, individualistas, o espírito de diferenciação profissional, progressão na carreira, competição e de conflito relaciona-se com a imposição de quotas para as qualificações de muito bom e excelente, sendo que aquilo que parece estar em jogo não será apenas ter um uma qualificação de muito bom ou excelente, mas, fundamentalmente, aceder a um lugar de quota. É, aliás, pelas mesmas razões que observámos que os docentes adotam posições de um claro engajamento burocrático estratégico com sentido adaptativo à "contingentação das duas classificações superiores que conferem direito a uma bonificação no ritmo de progressão na carreira e a um prémio de desempenho" (PORTUGAL, 2012).

Empiricamente, evidenciou-se que o quadro geral da avaliação é, per se, suscitador de espaços de poder, ou, como diz Robert Srour (1998, p.156-157), “[...] uma arena em que se digladiam forças interessadas em apropriar-se de bens socialmente escassos." Essa arena é caracterizada por jogos de bastidores, conluios, conchavos e tramas; hostilidades semideclaradas, pressões ocultas, ciladas, manobras; contrainformações e astúcias; arranjos de conveniência, traições e golpes palacianos, ritualizações e cerimoniais que podem, também, funcionar como poderosos fatores de controlo e poder organizacional, já que atingem “[...] o espírito e a sensibilidade dos humanos, predispondo-os para a submissão, ao introduzir uma disciplina" (FERNANDES, 1988, p.223) e o controlo organizacional. Tece-se, assim, uma complexa teia de conflitos decorrente da avaliação do desempenho, em que determinados conflitos são mais visíveis, e outros se mantém estrategicamente ocultos, subentendendo interesses individuais/grupais em colisão. O facto é que a avaliação do desempenho acaba por ser instrumentalizada (e, por isso, apropriada) pelos próprios atores no sentido de, no quadro das dinâmicas micropolíticas, consolidarem as suas posições de autoridade e a sua capacidade para exercer o seu poder sobre os outros.

Com os mesmos propósitos, e ainda dentro de uma aceção estrategicamente diferenciadora e ortogonal, a par do conflito entre pares, os dados empíricos denunciam a emergência de alianças ou a fundação de relações mais privilegiadas e estrategicamente estabelecidas entre os avaliados e outros docentes que detêm uma posição de considerável influência no "jogo" avaliativo. Efetivamente, na linha do conflito, pudemos verificar algumas manifestações de "alianças", na maior parte dos 
casos, concebidas e arquitetadas de forma a recortar sua gestão e execução com contornos, singular e estrategicamente, alinhados com o padrão normativo da avaliação, se bem que os bastidores dessas "coalizões" se mantenham demasiado ocultos na sensação de se poder estar a assistir a estratégias de adaptação das regras do sistema às expetativas e interesses dos atores, e não tanto de estes se adaptarem à lógica original do sistema. Os esforços destas alianças orientam-se para a dominação entre pares ou intergrupos de dimensão restrita, em que cada um tenta ocupar o lugar da "coalizão interna dominante", atendendo ao peso específico e capacidade de manobra dos seus elementos (SROUR, 1998, p.158).

\section{OS EFEITOS INSTRUMENTAIS NAS "NOVAS" LIDERANÇAS NO QUADRO DA GESTÃO E EXECUÇÃO DA AVALIAÇÃO DO DESEMPENHO DOCENTE}

Paradoxalmente, a tradução fragmentária que debatemos anteriormente ocorre no momento em que falamos de uma avaliação promotora da competição entre pares, enquadrada numa "nova" estrutura hierárquica da organização escolar, institucionalizada burocraticamente pelo efeito de regulamentação do sistema de avaliação do desempenho docente, que aqui configuramos como "novas" lideranças intermédias, com a responsabilidade exclusiva de tornar o desempenho docente avaliável a partir de um mandato administrativo burocrático do tipo centralista, correspondendo à premissa segundo a qual "[...] todas as escolas têm liberdade de ação desde que ajam restritivamente na direção do que está definido como necessário e suficiente pelo aparato regulador." (THIESEN, 2014, p.195). Dessas "novas" lideranças afetas à condução e gestão dos procedimentos avaliativos, destacamos, no próprio discurso oficial (PORTUGAL, 2012, grifo nosso),

Os avaliadores internos são selecionados segundo o princípio da hierarquização. Têm intervenção na avaliação o presidente do conselho geral, o diretor, o conselho pedagógico, a secção de avaliação do conselho pedagógico, o coordenador de departamento curricular e o avaliado. O Coordenador de departamento curricular, ou quem ele designar, tem como competência proceder ao acompanhamento e avaliação das dimensões "participação na vida da escola e relação com a comunidade" e a "formação contínua e desenvolvimento profissional". Por sua vez, a responsabilidade da avaliação na dimensão científico-pedagógica dos docentes em regime probatório, posicionados nos $2 .^{\circ}$ e $4 .^{\circ}$ escalões da carreira e aos candidatos à menção de Excelente, é atribuída aos avaliadores externos da mesma área científica do avaliado, detentores de formação prioritariamente especializada na área da avaliação do desempenho docente ou com experiência em supervisão pedagógica, posicionados 
na carreira num escalão preferencialmente superior ou, quando impossível, igual ao do avaliado.

Pela análise dos dados empíricos, é admissível referir que a racionalização e tradução periférica da burocracia central desenvolvem-se, invariavelmente, na ponderação dos ganhos e das perdas que intercede os contornos da resistência passiva e ativa ao padrão central da avaliação. Além disso, ocorre a percepção de que estamos perante um sistema, não apenas burocrático, mas, também, burocratizante da ação docente, por se transformar, exatamente, numa ação que se diz cumpridora (ou reprodutora) de determinados requisitos formais racionalizados a priori, levando os professores a agir em função do que as regras do sistema lhes exigem e, até, a protegerem-se de eventuais inconformidades à regra central da avaliação, assumindo-se a avaliação do desempenho como um território de alegada autonomia colocado "sob a mira dos standards educacionais" (THIESEN, 2014, p.192). Da mesma forma, podemos ressituar a avaliação do desempenho docente no quadro de

[...] uma imposição do conhecimento do 'eu' e do mundo que propicia ordem e disciplina aos indivíduos. Não há imposição através da força bruta, mas através da inscrição de sistemas simbólicos de acordo com os quais a pessoa deve interpretar e organizar o mundo e nele agir. (POPKEWITZ, 2008, p.186).

Empiricamente comprovada, a tendência para desenvolver um sentido de impugnação de alguns dos pressupostos originais da avaliação é, também, observada ao nível mais técnico, pelo que surge a perspetiva de que, em particular, os avaliadores internos e os avaliadores externos não apresentam a suficiente preparação técnica para desempenharem as funções que lhes são burocraticamente atribuídas, sendo algo que coloca em causa o pressuposto da superioridade técnica e a consequente "suscetibilidade técnica de perfeição" (WEBER, 1993) desses atores. Com efeito, a relativização dessa superioridade técnica conhece vários quadrantes de contestação, sendo um deles o dos critérios que determinam e regulamentam o perfil dos avaliadores e de outros intervenientes, como é o caso dos coordenadores de departamento curricular, pois que estando suportados por critérios, mais ou menos explícitos, de posição hierárquica, cargos detidos na estrutura organizacional e, consequentemente, de antiguidade, é claramente posta em causa precisamente pela recusa, por parte dos docentes, do pressuposto de que o docente alocado em níveis hierárquicos superiores e, consequentemente, mais antigo é, também, o mais competente. 
Além de tudo, desenvolve-se um sentido algo negativo da própria figura do avaliador tripartida pelas configurações de avaliador interno, externo e coordenador de departamento curricular, dado tratar-se do ator que adquire um maior imediatismo no quadro da avaliação do desempenho, suscitando a oportunidade para surgirem críticas em torno da imagem de autoridade formal de que se reveste e, consequentemente, do tipo de uso de poder que os atores, especialmente na situação de "avaliado", passam a temer, com claras influências ao nível do clima escolar, que se começa a caracterizar pouco amistoso, tendencialmente mais conflituoso e algo turbulento, portador de relações interpessoais mais distantes e diferenciadoras, especialmente ao nível do estatuto profissional e ao nível de alguma pressão exercida sobre os docentes avaliados.

Por outro lado, o facto de se assistir a uma quotização das qualificações mais elevadas leva a que as progressões ditas mais rápidas estejam, fatalmente, ao alcance de apenas alguns, ganhando plausibilidade o facto de os docentes impossibilitados de aceder a um lugar de quota desenvolver recursos estratégicos (individuais ou grupais) de índole micropolítica, embora com a necessária adaptação burocrática, na gestão da sua própria carreira. Aliás, o próprio discurso oficial (PORTUGAL, 2012) assim o explicita:
A diferenciação na avaliação faz-se com recurso a cinco menções qualitativas (Insuficiente, Regular, Bom, Muito bom e Excelente). De modo análogo ao regime de avaliação do desempenho aplicável aos funcionários e agentes da Administração Pública, procede -se a uma contingentação das duas classificações superiores que conferem direito a uma bonificação no ritmo de progressão na carreira e a um prémio de desempenho.

Ao mesmo tempo, constrói-se um cenário de "hipocrisia organizada" (COSTA, 2007), que se vai institucionalizando e naturalizando, acabando por influenciar a construção das representações e da instrumentalização que os docentes vão desenvolvendo em torno do seu mundo profissional. Isto quer dizer que, não havendo possibilidade de todos os docentes conseguirem ocupar um lugar de quota através de um desempenho que efetivamente corresponda às qualificações mais elevadas, ou porque mesmo apresentando um desempenho conforme, o número de quotas mostra-se insuficiente para contemplá-los, as vias alternativas tendem a surgir sob a forma de coalizões, alianças, disputas e jogos micropolíticos (SROUR, 1998), que tendem a diluir ou a reequacionar os limites formais que medeiam o acesso àquelas qualificações e 
respetivos benefícios, inclusive, uma real utilidade e efetividade da avaliação, com referência aos propósitos explicitados no discurso oficial que a suporta.

Do ponto de vista da administração e gestão periféricas, a ausência de autonomia do agrupamento e dos seus docentes retira um peso muito substancial ao sentido e ao significado das referências locais de cariz mais informal e espontâneo, com propensão para serem asfixiadas pela dimensão formal do sistema de avaliação. Sendo "um sistema que vem muito de cima", tende a institucionalizar-se sob o signo paradoxal do desajustamento à realidade, emergindo como um aspeto que denuncia o caráter disfuncional do aparelho centro burocrático da avaliação, mesmo admitindo que as referências centrais têm uma considerável utilidade na conceção e esquematização do sistema de avaliação. Efetivamente, as ambições autonómicas a que os docentes aspiram como forma de melhor gerirem a operacionalização das dimensões e indicadores da avaliação do desempenho docente mantêm-se em contracorrente com aquilo que, eles próprios, consideram ser as dimensões de avaliação privilegiadas pelo Ministério da Educação, alegando que se trata de uma avaliação muito mais alinhada com mecanismos de controlo da ação docente, em que a avaliação do desempenho emerge como mecanismo subtil que visa promover a gestão e instauração das políticas educativas, com particular destaque para a administração e gestão de recursos humanos educativos, segundo a clássica regulação do tipo top-down (BOLÍVAR, 2000).

Além disso, a avaliação, no dizer dos docentes, concretiza um conceito operacional de autonomia do agrupamento, nomeadamente em termos de produção de referências avaliativas, não tanto como um direito fundamental dos atores escolares, mas entendida mais como um privilégio cedido pelas hierarquias de topo, privilégio esse que é apresentado, por um lado, como um mecanismo promotor de processos gestionários periféricos controlados a partir do centro e, por outro, como um conjunto de limitações práticas ao seu exercício.

Consequentemente, surge a tendência para rever e atualizar o paradigma da “prestação de contas" na perspetiva de "extração de contas" dependente, apenas, do necessário comprometimento desses docentes burocraticamente tipificados como os "recolectores" da "informação de base" (LIMA, 2011, p.37), a quem é exigido o respetivo tratamento em linha com os pressupostos da administração central, indiciando, ao mesmo tempo, um acentuado recuo na autonomização do agrupamento e dos seus atores. Algo, aliás, observável pelo engajamento burocrático e normativo dos gestoresavaliadores responsáveis pela liderança, gestão e aplicação do sistema de avaliação. 
Efetivamente, foram muito claras as alegações dos atores quanto ao efeito executório da prescrição central que, a partir do referencial central, impôs um grau elevado de comprometimento desses atores - deslizando para o incremento de "novas lideranças" da periferia, com a responsabilidade de organizar o tipo de resposta que o discurso oficial exige que se concretize, enredando-os no quadro de um referencial alinhado com a "dominação legal" composto por regras heterónimas e com a "expectativa programática" da administração central, que impõe uma alienação tipicamente gestionária da secção de avaliação de desempenho docente do conselho pedagógico, dos coordenadores de departamento e dos avaliadores internos e externos, para além de uma clara submissão dos avaliados a esses pressupostos gestionários.

Exemplo disso são as tendências introduzidas pela avaliação do desempenho docente para o poder central promover padrões racionalizadores de gestão escolar, em geral, e do corpo docente, em particular, visando à eficácia, à eficiência do sistema, das organizações escolares e dos atores, mantendo em seu poder o controlo sobre os fins e resultados da educação e respetiva ação docente. Neste caso, reputa-se que a avaliação do desempenho docente seja, fundamentalmente, fruto da "ditadura administrativa" (BEETHAM, 1987, p.11 e p.14).

Aliás, a perceção da avaliação do desempenho - enquanto mecanismo de controlo da ação docente - é desenvolvida em detrimento da alegada função formativa dessa mesma avaliação, contrastando com a perceção de que os resultados da avaliação do desempenho não têm emergido como uma mais valia em termos de contributo formativo e de desenvolvimento do profissionalismo dos professores, sugerindo-se, mesmo, por parte de alguns docentes, que aquele controlo chega a assumir contornos de punição, que tende a dar algum destaque a uma alegada desacreditação da escola pública e do próprio reconhecimento social e profissional dos professores.

Consequentemente, o "velho" debate da centralização versus descentralização é caracterizado por aspetos típicos da centralização burocrática das políticas educativas, instrumentalizando-se a avaliação como mecanismo de recentralização administrativa da educação e, ao mesmo tempo, promovendo um engajamento burocrático - tipicamente reprodutor - dos atores que assumem a liderança e o protagonismo da gestão e execução do sistema de avaliação, sendo inseridos em dinâmicas organizacionais e gestionárias de caráter obrigatório .

Também por isso evidenciamos, numa lógica de top-down, um cenário de participação, de envolvimento e de liderança dos elementos da secção de avaliação 
de desempenho docente do conselho pedagógico dos próprios diretores de departamento e ademais tipificações de avaliadores, caracterizado pela institucionalização e normalização de uma tecnologia de extração de contas, decorrente, como vimos, de um quadro avaliativo altamente prescritivo e regulado a partir do centro, mas liderado por líderes recém e burocraticamente formatados, instrumentalizados para praticar, gerir e executar um modelo de avaliação centralista a partir da periferia, mas comandado à distância (LIMA, 1994; ESTÊVÃO, 1995).

\section{CONCLUSÃO}

Ainda que com alguma força de síntese, concluímos que, pela relevância dos dados empíricos, na base dos quais construímos este ensaio crítico sobre o impacto da avaliação de professores nas dinâmicas desenvolvidas pelas lideranças intermédias institucionalizadas na senda das novas políticas de avaliação do professorado, subjazem à institucionalização das políticas e práticas de avaliação do desempenho docente importantes transformações ao nível da "velha" hierarquia do corpo docente, observando-se uma clara tendência para a sua verticalização, muito por causa da emergência de novas relações de poder, de autoridade e de influência na escola e na sala de aula. Efetivamente, vimos que o arranjo macroinstitucional da avaliação sacraliza o arquétipo da "senioridade" e respetiva superioridade técnica e hierárquica como forma de promover uma reestruturação das relações socioprofissionais que passam a caracterizar a hierarquia do pessoal docente, sendo esta a via fundamental que marca a tendência para a verticalização das relações hierárquicas estabelecidas entre os docentes. Concomitantemente, concretiza-se um esquema de engajamento organizacional de onde sobressaem as designadas "lideranças emergentes", sedeadas num novo locus de autoridade e poder legais de onde sobrevém, também, o efeito da subordinação hierárquica dos avaliados. Assim se sintetiza a referida reverticalização da estrutura hierárquica do corpo docente.

Decorrentemente, a perspectiva (metafórica) organizacional que sobressai deste quadro conclusivo emerge sob duas orientações oficiais: ao associarmos as políticas e práticas de avaliação do desempenho docente à metáfora do "controlo à distância" da ação docente e do próprio funcionamento do agrupamento, por um lado, assistimos a uma instrumentalização das estruturas organizativas do agrupamento em prol da (re)centralização e da (re)burocratização e, por outro, da 
despolitização dos contextos e processos de tomada de decisão educativa, com especial incidência no quadro da referencialização da avaliação de professores e educadores, retomando a ideia de escola perspectivada como "agência de gestão" da esfera central. Na verdade, as políticas e práticas de avaliação do desempenho docente concretizam um modelo organizacional e o respetivo projeto políticopedagógico amplamente racionalizados, planificados há já algumas décadas. Daí dizermos que se trata de um quadro de políticas e práticas que se mantêm no âmbito do paradigma centralista da administração e gestão da escola pública, atuando, aliás, como reforço e consolidação desse paradigma.

Além disso, não nos é estranha a imagem de "empresa" associada ao tipo de instrumentalização a que a avaliação do desempenho e as dinâmicas e prerrogativas gerencialistas que se impõem às "novas" lideranças da periferia. Com efeito, assistimos à introdução de importantes transformações, que sinalizam a instrumentalização da avaliação do desempenho docente para, segundo os pressupostos da "narrativa do management" (RAMALHO, 2012, p.264), introduzir, no agrupamento de escolas que observámos, determinados padrões de gestão próprios do mundo empresarial. Aliás, algumas das funções específicas da avaliação do desempenho, embora por vezes se mostrem implícitas, decorrem desses mesmos padrões, impondo determinadas mudanças de ordem organizacionais perfeitamente adaptadas aos valores da gestão estratégica, da competitividade, da eficiência, da eficácia e da qualidade ajuizados pela lógica da prestação ou, até mesmo, de extração de contas.

\section{ASSESSMENT TEACHER PERFORMANCE AND MANAGEMENT SCHOOL: REFLEXES IN THE MIDDLE MANAGEMENT AND EFFECTS OF NEW VERTICALIZATION IN THE HIERARCHY OF THE SCHOOL}

ABSTRACT: Arising from a research already done for us, within a doctoral thesis, we sought, in this text, making a critical approach to the relationship between the performance evaluation of teachers and the emergence of "new" intermediary leaderships of a school cluster, as part of the basic education system in Portugal, alluding to how these "new" leaderships have come to occupy their niches in the administration and management of portuguese elementary school. Congruently, presents itself in the configuration of a social critical essay, imminently, with a conclusive character of that same study, also supported by an analytic theoretical model, which theoretically subsidized the research. Overall, we inscribe this our assay in the specific methodology of the case study, having resorted to different techniques of 
research and data gathering, in particular, the questionnaire, the interview, critical personal documents and analysis of official documents originating from the central government (legislation) and school cluster observed. Conclusively, we observed the perception of some fragilities and even ruptures with the recognition and legitimation of those intermediary leaderships, especially where they are identified as leaderships who are assigned responsibility to management and implementation of the evaluation.

KEYWORDS: Teacher evaluation. Intermediary leaderships. Bureaucracy. School management.

\section{REFERÊNCIAS}

BALL, S. La micropolítica de la escuela: hacia una teoria de la organización escolar. Madrid: Centro de Publicaciones del Ministério de Educación y Ciencia. Barcelona: Paidós, 1989.

BEETHAM, D. Burocracia. Lisboa: Estampa, 1987.

BERNARDES, C. Sociologia aplicada à administração. São Paulo: Atlas, 1990.

BOLÍVAR, A. O lugar da escola na política curricular atual: para além da reestruturação da descentralização. In: SARMENTO, M. (Org.). Autonomia de escola: políticas e práticas. Porto: Asa, 2000. p.157-190.

COSTA, J. Os projetos na escola: uma leitura crítica através da metáfora da hipocrisia organizada. In: COSTA, J. Projetos em educação: contributos de análise organizacional. Aveiro: Universidade de Aveiro, 2007. p.97-118.

CROZIER, M.; FRIEDBERG, E. L'acteur et le système: les contraintes de l'action collective. Paris: Éditions du Seuil, 1977.

ESTÊVÃO, C. O novo modelo de direção e gestão das escolas portuguesas: a mitologia racionalizadora de uma forma organizacional alternativa. Revista Portuguesa de Educação, Braga, v.8, n.1, p.87- 98, 1995.

FERNANDES, A. Os fenómenos políticos: sociologia do poder. Porto: Afrontamento, 1988.

GIBSON, J.; IVANCEVICH, J.; DONNELLY, Jr. Organizações. São Paulo: Atlas, 1988.

HADJI, C. Avaliação: regras do jogo. Porto: Porto Ed., 1994.

JAEHN, L.; FERREIRA, M. Perspectivas para uma história do currículo: as contribuições de Ivor Goodson e Thomas Popkewitz. Currículo sem Fronteiras, [S.1.], v.12, n.3, p.256-272, set./dez. 2012. Disponível em:

<http://www.curriculosemfronteiras.org/vol12iss3articles/jaehn-ferreira.pdf >. Acesso em: 3 maio 2014. 
LIMA, L. Conceções de escola: para uma hermenêutica organizacional. In: LIMA, L. (Org.). Perspetivas de análise organizacional da escola. Gaia: Fundação Manuel Leão, 2011. p.15-57.

Reformar a administração escolar: a recentralização por controlo remoto e a autonomia como delegação política. Revista Portuguesa de Educação, Braga, n.8, p.57-71, 1994.

LUDKE, M.; ANDRÉ, M. Pesquisa em educação: abordagens qualitativas. São Paulo: Editora Pedagógica e Universitária, 1986.

MARTIN, J. Cultures in organizations. New York: Oxford University Press, 1992.

MARTIN, J.; SIEHL, C. Organizational culture and counterculture: an uneasy symbiosis. Organizational Dynamics, New York, v.12, n.2, p. 52-64, 1983.

MORGAN, G. Imagens da organização. São Paulo: Atlas, 1996.

NEVES, J. Clima e cultura organizacional. In: FERREIRA, F.; NEVES, J.; CAETANO, A. Manual de psicossociologia das organizações. Amadora: McGrew-Hill, 2001. p.431-468.

OLIVEIRA, M. E. N. Processo de reestruturação curricular: do discurso democrático ao corporativismo docente. Currículo sem Fronteiras, [S.1.], v.13, n.2, p.320-339, maio/ago. 2013. Disponível em:

<http://www.curriculosemfronteiras.org/vol13iss2articles/oliveira.pdf>. Acesso em: 3 maio 2014.

ORTSMAN, O. Mudar o trabalho: as experiências, os métodos, as condições de experimentação social. Lisboa: Fundação Calouste Gulbenkian, 1984.

POPKEWITZ, T. História do currículo, regulação social e poder. In: SILVA, T. (Org.). O sujeito da educação: estudos foucaultianos. Petrópolis: Vozes, 2008. p.173-210.

PORTUGAL. Decreto-Lei n ${ }^{\circ} 41$, de 21 de fevereiro de 2012. Procede à alteração do estatuto da carreira dos educadores de infância e dos professores dos ensinos básico e secundário, com efeito de regulamentação da avaliação do desempenho docente. Diário da República, [Lisboa], 21 fev. 2012. 1. a série, n. 37, p. 829-855.

RAMALHO, H. Escola, professores e avaliação: narrativas e racionalidades da avaliação do desempenho docente na escola básica portuguesa. 2012. 657f. Tese (Doutorado em Ciências da Educação) - Universidade do Minho, Instituto de Educação, Braga, 2012.

SANTOS GUERRA, M. La evaluación: un proceso de diálogo, comprensión y mejora. Málaga: ALJIBE, 1995.

SROUR, R. Poder, cultura e ética nas organizações. Rio de Janeiro: Campus, 1998. 
THIESEN, S. Currículo e gestão escolar: territórios de autonomia colocados sob a mira dos standards educacionais. Currículo sem Fronteiras, [S.1.], v.14, n.1, p.192-202, jan./abr. 2014. Disponível em:

<http://www.curriculosemfronteiras.org/vol14iss1articles/thiesen.pdf >. Acesso em: 28 maio 2014.

WEBER, M. Economía y sociedad: esbozo de sociología comprensiva. México. Fondo de Cultura Económica, 1993. 